\title{
EVALUATION OF THE POTENTIAL TOXICITY OF TAU- FLUVALINATE ON ADULT HONEYBEES APIS MELLIFERA, UNDER LABORATORY CONDITIONS
}

\author{
ALJEDANI, D. M. \\ Department of Biological Sciences, College of Science, University of Jeddah, Jeddah, Saudi \\ Arabia \\ (e-mail:dmaljedani@uj.edu.sa)
}

(Received $10^{\text {th }}$ Sep 2021; accepted $28^{\text {th }}$ Oct 2021)

\begin{abstract}
In this study, honeybees have been exposed to tau-fluvalinate to assess survival and determine the concentration at which the highest mortality occurred, and the extent to which this pesticide affects the internal organs of the digestive system. Four different concentrations of tau-fluvalinate were used (3.6, 6.25, $12.5,25.5 \mathrm{mg} / \mathrm{L}$ ) on the forager honeybee worker. The adult workers were under continuous observation and assessed after $12,24,48,72$, and $96 \mathrm{~h}$ following the treatment by $\mathrm{LC}_{50}$ of tau-fluvalinate to determine adult workers' longevity. According to the results of this study, a $13.700 \mathrm{mg} / \mathrm{L}$ concentration of tau-fluvalinate kills half of the individuals. Also, there is a direct relationship between the time of exposure to the pesticide and its effect on the survival of adult workers. Also, the midgut was found to be torn and incoherent and showed signs of shrinking. The colour of the ileum became transparent also after the treatment, its walls shrunk, and thin lines appeared. Also, it was found that the rectum, after the treatment had very thin walls that were almost lacerated. This provides a useful indicator of the possible effect of tau-fluvalinate, which was found to have negative effects on worker body parameters and bee anatomy.
\end{abstract}

Keywords: Acaricide, Apis mellifera jemenatica, concentrations, digestive system, longevity, mortality

\section{Introduction}

The social insect honeybee (Apis mellifera) is the most critical pollinator on the globe, the health of Apis mellifera colonies has been a major concern in recent years (VanEngelsdorp et al., 2017). Many factors, both biotic and abiotic, affect honeybee colonies. Varroa mites (Varroa destructor) are one of the biotic causes that have a heavy adverse effect on honeybees all over the world. As described by Rangel and Tarpy (2016) these mites were thought to be one of the causes of colony collapse disorder (CCD). For decades, the ectoparasitic mite Varroa destructor has become the most serious issue in beekeeping around the world. The Varroa mite's destructive effect on Apis mellifera has become especially evident in recent years, with a substantial increase in controlled colony mortality and global honeybee population declines (Potts et al., 2010).

Varroa control has been developed and tested using a variety of natural, mechanical, and chemical methods (Allam et al., 2021). Beekeepers usually rely on a reduced set of acaricides to manage the parasite, the pyrethroids tau-fluvalinate or flumethrin, the organophosphate coumaphos, and the formamidine amitraz. However, the evolution of resistance in the mite populations is leading to an unsustainable scenario with almost no alternatives to reach an adequate control of the mite (Sara et al., 2021). Chemical materials (i.e. acaricides) are, however, almost always the most efficient method. But the problem with using acaricides is the high residue level in bee products; additionally, acaricides used in beehives affect Varroa mites and honeybees. Unfortunately, acaricides' long-term effects on honeybees have yet to be identified (Semkiw et al., 2013). 
Contaminants can alter organism behavior and, as a result, their ability to survive. The active ingredient in a pesticide widely used in North America to control Varroa destructor mites in honeybee (Apis mellifera) colonies is tau-fluvalinate, the effects of fluvalinate on honeybees are unknown to now (Frost et al., 2013). The effects of taufluvalinate, which is the active ingredient of Apistan $\AA$, were investigated by Davies et al. (2007) they found the sensitivity of honeybees to stimuli and the mortality of honeybees of fluvalinate, which is a form of neurotoxin that acts as an agonist for voltage-gated sodium channels to prolong membrane depolarization.

Honeybees nurse larvae inside the hive, while worker bees forage on pollen and nectar from flowers outside the hive as they grow older (Vojvodic et al., 2013). The adult gut is divided into four main organs (crop, midgut, ileum, and rectum), each of which serves a different role in catabolism and absorption (Kakamand et al., 2008). Furthermore, many pathogens begin to be diagnosed through the internal tissues and structures (Gisder and Genersch, 2020). Moreover, honeybee Pharmacology examines the effects of different drugs and chemical substances experienced by the honeybee while foraging for nectar, pollen, propolis, and water, as well as the effects of drug treatments applied to the colony deliberately and is discussed in a comparative manner using the individual honeybee as a model for extrapolation of these principles to the superorganism (Davidson, 2021).

A variety of chemicals, including tau-fluvalinate, are available for the management of Varroa mites in honeybee colonies. The optimal dose of these chemicals should provide the best Varroa control with the least amount of harm to honeybees. Honeybees are likely to be harmed as a result of the high doses (Allam et al., 2021). Fluvalinate residues detected in both honey and wax collected from colonies treated with the strips method exceeded the maximum residue limits $(0.05 \mathrm{ppm}$ for both honey and wax) according to the EU pesticides database (Abd El-Wahab et al., 2021). So, further research has been needed to do on the impact of these chemicals on honeybees. As a result, assessing the possible effects of acaricides on honeybees is important. So, this study aimed into the effects of sub-lethal concentrations of a common acaricide (tau-fluvalinate) on the survival parameters of honeybee workers who were exposed to it and the extent to which this pesticide affects the internal organs of the gastrointestinal tract.

\section{Materials and methods}

\section{Honeybees and insect cells}

The present study was carried out in the apiary and a lab in March 2021 on adult worker honeybees (Apis mellifera jemenatica) (Hymenoptera: Apidae), which were collected from an apiary at the Faculty of Environmental Sciences research station in Saudi Arabia. It has been preserved in a pesticide-free environment and handled according to traditional beekeeping practices. The colonies had not undergone any chemical therapies for at least six months. Visual observation was used to monitor the colonies' health weekly until research. It was then moved to the University of Jeddah's Laboratory of Entomology.

\section{Bee rearing and feeding}

Emerging brood frames were collected from colonies and placed in an incubator at $35{ }^{\circ} \mathrm{C}$ and $50 \%$ relative humidity. Groups of 450 newly emerged workers were gathered 
and placed in $15 \times 15 \times 15 \mathrm{~cm}$ wood cages with wire mesh and were followed until they reached the age of foraging honeybee workers. For breeding, wooden boxes were used, with one side of the wooden box covered in metal wire mesh and the other with glass. The workers were fed. On the top side of the cage, two plastic medical syringes $(50 \mathrm{ml})$ were inserted, one with water and the other with a $50 \% \mathrm{w} / \mathrm{v}$ sugar solution, added to it different concentrations of the pesticide(Aljedani, 2017). Also, in the control group sugar solution was introduced only, without any insecticide. In addition, they were given pollen. In three cages per treatment (Ardalani et al., 2021), and the chronic oral toxicity test on adult worker honeybees under laboratory conditions over an exposure period of 10 days was based on the OECD Acute Oral Toxicity Test, described by OECD (2017).

\section{Tau-fluvalinate}

The tau-fluvalinate pyrethroid, a subset of fluvalinate isomers, was the first synthetic varroacide approved for use in honeybee colonies in the United States (Johnson et al., 2010). The tau-fluvalinate has been commonly used to control Varroa mites. Four different concentrations (3.6, 6.25, 12.5, $25.5 \mathrm{mg} / \mathrm{L}$ ) of tau-fluvalinate (Qi et al., 2020) were used.

Tau-fluvalinate is the ISO common name for (RS)- $\alpha$-cyano-3-phenoxybenzyl N-(2chloro- $\alpha, \alpha, \alpha$-trifluoro-p-tolyl)-D-valinate (IUPAC). Tau-fluvalinate represents a 1:1 mixture of two isomers ( $\mathrm{R}-\alpha$-cyano and $\mathrm{S}-\alpha$-cyano isomers) whereby fluvalinate consists of four isomers (Brancato et al., 2018).

Product name: tau-Fluvalinate, Pestanal ${ }^{\mathrm{TM}}$, analytical standard (96.9\% purity).

Brand: Sigma-Aldrich, Product of Switzerland.

Formula: $\mathrm{C}_{26} \mathrm{H}_{22} \mathrm{CIF}_{3} \mathrm{~N}_{2} \mathrm{O}_{3}$

For structural formula, see Figure 1.

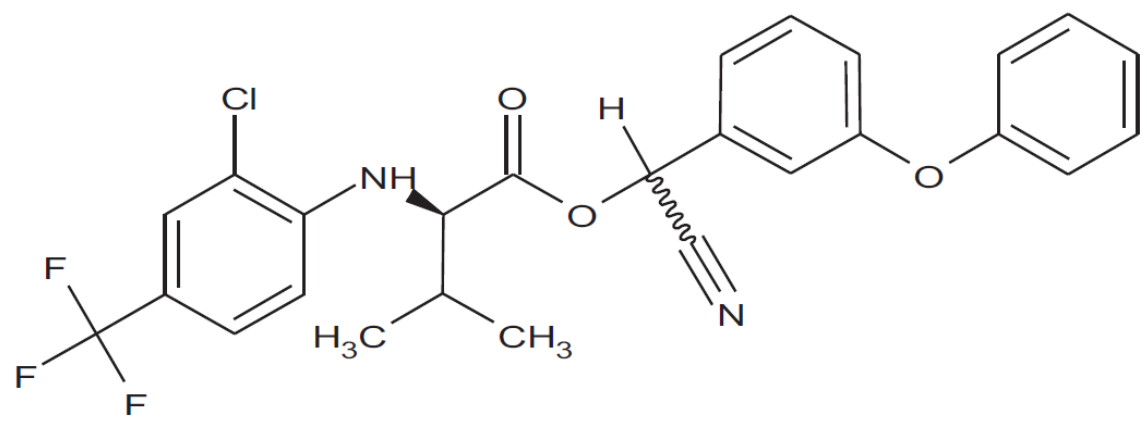

Figure 1. Structural formula of tau-fluvalinate

\section{Procedures for conducting research}

In this analysis, forager honeybee workers Apis mellifera jemenatica were exposed to different concentrations of tau-fluvalinate, and the benchmark for dose was prepared by diluting them in $95 \%$ ethanol $\mathrm{LD}_{50}(2.0 \mathrm{mg} / \mathrm{ml})$ on the day of treatments. The aim was to see how long they survived after being exposed to it and the extent to which the internal organs of the gastrointestinal tract are affected by this pesticide. 


\section{The mortality}

After incubation and feeding on sucrose adult honeybees were orally exposed to four different concentrations $(3.6,6.25,12.5,25.5 \mathrm{mg} / \mathrm{L})$ of tau-fluvalinate. The mortality was assessed, and the lethal concentration $\left(\mathrm{LC}_{50}\right)$ was determined. The survival data on caged bees under exposure to tau-fluvalinate had in addition to a control group $(0.00$ $\mathrm{mg} / \mathrm{L}$ ). If the adults could not move after being prodded with a fine hairbrush, they were considered dead.

\section{Longevity}

The adult honeybee workers were followed up and assessed after 12, 24, 48, 72, and $96 \mathrm{~h}$, after treatment by $\mathrm{LC}_{50}$ of tau-fluvalinate, in addition to a control group (0.00 $\mathrm{mg} / \mathrm{L})$ to determine adult workers' longevity.

\section{The anatomical structure}

\section{Internal anatomy in the alimentary canal of adult workers}

A group of the forager honeybee workers was exposed to concentration $\mathrm{LC}_{50}$ for four days, where honeybee workers were fed for 4 days with concentration $\mathrm{LC}_{50}$, and then surviving workers were frozen and then stored at $-4{ }^{\circ} \mathrm{C}$ until dissection, in addition to a control group $(0.00 \mathrm{mg} / \mathrm{L})$.

For all insects, preserving as much tissue as possible without degradation is crucial, so freezing and converting the cadavers to $70 \%$ ethanol allows for short-term storage and later dissection.

A good understanding of bee internal anatomy is needed to conduct these dissections; the anatomy of Apis mellifera is well described by Baker et al. (1982) Dissection techniques are defined, and the methods are described by Carreck et al. (2013).

Sections of the alimentary canals (midgut (Mig), ileum (IL), Rectum (Rect)) in honeybee workers were dissected, in preparation for examination and imaging was carried out with an anatomy microscope connected to a digital camera (Light microscope with Digital camera (Canon power shot S80 DC150).

\section{Statistical analysis}

After determining the correction rate of death using Abbott's formula (Abbott, 1925) the findings were evaluated using the toxicity value, Chi-Square test, and values of $\mathrm{LC}_{50}$ were calculated and drawing mortality regression lines Ldp line by a computer program (Ldp Line). Besides, results were obtained as mean \pm Standard deviation (std) using SPSS software (version 22.0) according to variance (ANOVA). Statistical significance was tested using Student's t-test between two groups and one-way ANOVA for more than two groups and was compared at the 0.05 level by a program SPSS. Statistical differences between each treatment and control were determined separately at each experimental time point to determine adult workers' longevity after treatment by $\left(\mathrm{LC}_{50}\right)$ of tau-fluvalinate.

\section{Results}

When foraging honeybee workers Apis mellifera jemenatica were exposed to different concentrations of tau-fluvalinate, the long-term survival of honeybees was 
tested. The present result of this study showed the extent to which anatomical structure of the internal organs of the gastrointestinal tract is affected by this pesticide after treatment by $\left(\mathrm{LC}_{50}\right)$ of tau-fluvalinate.

\section{The mortality}

In this study, laboratory toxicity was evaluated for tau-fluvalinate of this pesticide $96 \mathrm{~h}$ after the treatment of the forager honeybee workers by tau-fluvalinate. By analyzing the toxicological results of tau-fluvalinate it was found that there was a direct proportion between the tested concentrations and the mortality percentages of the treated adult workers with these concentrations. The results also showed that the effective concentrations of the tau-fluvalinate were at $(3.6,6.25,12.5,25.5 \mathrm{mg} / \mathrm{L})$. Death rates for treated adult workers ranged from $28 \%$, the lowest concentration to $65 \%$ the highest concentration as presented in Table 1. On the other hand, the laboratory toxicological lines of the tau-fluvalinate and the statistical constants derived from them showed the difference of the lethal concentration values for half of the number of tested adult workers $50 \%, 90 \%$ and for $99 \%$, which is known as $\mathrm{LC}_{50}, \mathrm{LC}_{90}$ and $\mathrm{LC}_{99}$, in the treatment with the tau-fluvalinate pesticide 13.700, 175.628, $1404.975 \mathrm{mg} / \mathrm{L}$, respectively. The confidence intervals ranged from the minimum to the upper limit corresponding to these concentrations from $(10.615,19.541 \mathrm{mg} / \mathrm{L}),(80.282,856.068$ $\mathrm{mg} / \mathrm{L})$, and $(380.443,20474.99 \mathrm{mg} / \mathrm{L})$ respectively, at a 95\% confidence (Table 2). The concentration of tau-fluvalinate that caused 50 percent of forager honeybee workers to die after being exposed to it $\left(\mathrm{LC}_{50}=13.700 \mathrm{mg} / \mathrm{L}\right)$, (Fig. 2).

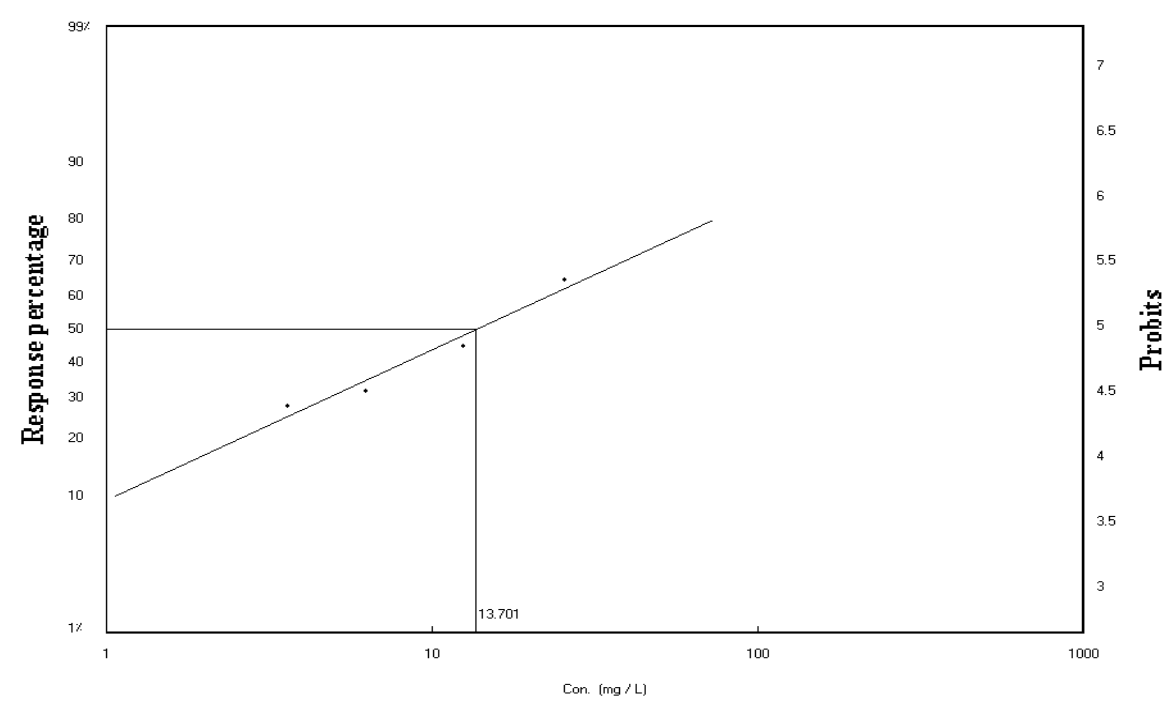

Figure 2. Lethal concentration $\left(L C_{50}\right)$ values after $96 \mathrm{~h}$ of exposure of forager honeybee workers to different concentrations of tau-fluvalinate

\section{The longevity}

In the current study, which evaluated the toxicity of the effects of tau-fluvalinate on adult honeybee workers after being affected by lethal half concentration $\left(\mathrm{LC}_{50}=13.700 \mathrm{mg} / \mathrm{L}\right)$, after the 12, 24, 48, 72, and 96 hours of treatment, to determine the long-term effects of taufluvalinate on adult honeybee workers. The group that was not treated with any type of insecticide (control group $(0.000 \mathrm{mg} / \mathrm{L})$ and were fed naturally did show some type of 
changes and death, but these were within normal limits continued to the end of the experiment. Also, it was evident from the results of the current study that there is a direct relationship between the time of exposure to the pesticide and its effect on the survival of adult workers. The greater the duration of exposure to this pesticide was, the fewer the number of adult workers and the lower their chance of survival was. The death rate after $12 \mathrm{~h}$ in the control group was 1 while 9 in the pesticide-treated group. On the other hand, after 96 $\mathrm{h}$, the number of dead individuals in the control group reached 11 and rose to 43 in the pesticide-treated group (Fig. 3).

Table 1. Relation between different concentrations of tau-fluvalinate and mortality of the forage honeybee workers death after $96 \mathrm{~h}$ of treatment

\begin{tabular}{c|c|c|c|c}
\hline $\begin{array}{c}\text { Con. } \\
(\mathbf{m g} / \mathbf{L})\end{array}$ & Log (Con. * 10) & Observed response \% & Linear response\% & Linear probit \\
\hline 0.00 & 0.000 & 0.000 & 0.000 & 0.000 \\
3.6 & 0.556 & 28 & 25.097 & 4.328 \\
6.25 & 0.795 & 32 & 34.669 & 4.605 \\
12.5 & 1.096 & 45 & 48.163 & 4.953 \\
25.5 & 1.406 & 65 & 62.248 & 5.312 \\
\hline
\end{tabular}

Table 2. $L C_{50}, L C_{90}$, and $L C_{99}$ values, slope values for tau-fluvalinate toxicity line, and maximum and minimum values

\begin{tabular}{|c|c|c|c|c|c|}
\hline Slope & Chi & $\mathbf{r}$ & $\mathrm{LC}_{50}$ & $\mathrm{LC}_{90}$ & LC99 \\
\hline 1.1568 & 1.490 & 0.977 & \multirow{2}{*}{13.7005} & \multirow{2}{*}{175.628} & \multirow{2}{*}{1404.975} \\
\hline$+/-0.205$ & Tabulated 6 & Tabulated 0.95 & & & \\
\hline \multicolumn{3}{|c|}{ Lower limit $(\mathrm{mg} / \mathrm{L})$} & 10.615 & 80.282 & 380.443 \\
\hline \multicolumn{3}{|c|}{ Upper limit (mg/L) } & 19.541 & 856.068 & 20474.99 \\
\hline
\end{tabular}

Chi-Square (Chiinv) (Chi), probability (p), correlation coefficients (r)

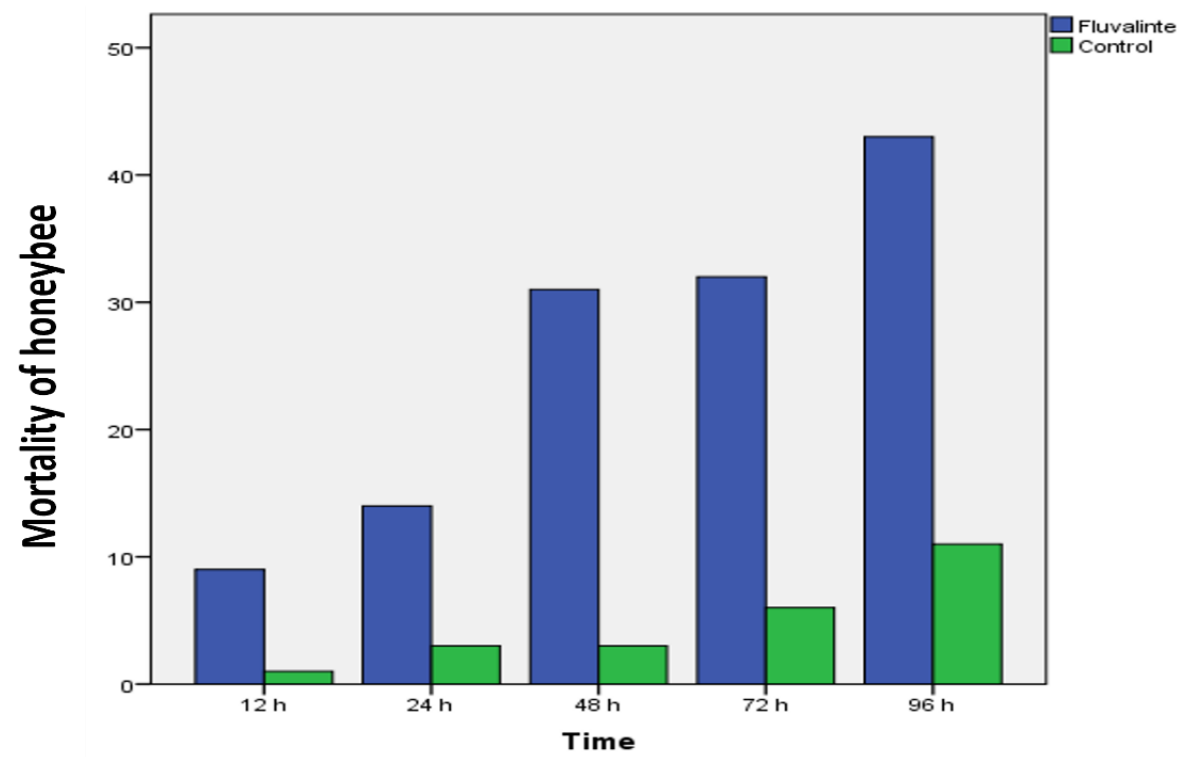

Figure 3. Comparison of the effect of tau-fluvalinate against forager honeybee worker using the mortality of $L C_{50}=13.7005 \mathrm{mg} / \mathrm{L}$ at different times $(h)$ 
Furthermore, a group of adult honeybee workers exposed to tau-fluvalinate had a clear impact on its survival. In the control group, the significance ( $p$-value) value reached 0.05 high significance at $\mathrm{P}<0.05$. While the group treated with tau-fluvalinate reached 0.01 . On the other hand, the value of (Mean \pm SD), in the control group reached $(4.800 \pm 3.898)$. While the group treated with tau-fluvalinate reached $(25.800 \pm 13.989)$ (Table 3).

Table 3. Value of longevity of foragers honeybee workers at $96 \mathrm{~h}$ after treatment by taufluvalinate at $95 \%$ confidence interval of the difference

\begin{tabular}{c|c|c|c|c|c|c|c}
\hline Treatment & Sig. (2 tailed) & $\mathbf{t}$ & Mean & SD & SE & Minimum & Maximum \\
\hline Control & 0.051 & 2.753 & 4.800 & 3.898 & 1.743 & 1.000 & 11.000 \\
Fluvalinate & 0.015 & 4.124 & 25.800 & 13.989 & 6.256 & 9.000 & 43.000 \\
\hline
\end{tabular}

Std. deviation (SD), Std. error mean (SE), Sig. at P $<0.05$

\section{The anatomical structure}

\section{Internal anatomy in the alimentary canal of the adult workers}

External anatomical structure of the forager honeybee workers was described and compared between a group of forager honeybee workers exposed to concentration $\left(\mathrm{LC}_{50}\right)$ for four days, and a control group $(0.00 \mathrm{mg} / \mathrm{L})$.

In the first set (the control group) of results were obtained by the anatomical study conducted on the gastrointestinal tract of honeybee workers, that the midgut, which is an organ that follows the gut, and folds into the body cavity in the form of a U-shape, and occupies a large area of the abdominal cavity of the honeybee worker. Among the results of the autopsy on honeybee workers, the following was noted: the midgut is firm and has a homogeneous mass so that the folds almost disappear and are yellow.

Overall, these results of the anatomical study of honeybee workers indicate that the hindgut region is distinguished into two regions; one, the anterior segment, known as the ileum, is a fine, small, and convoluted segment (small intestine), which gets rid of body remnants and wastes and absorbs water, and food residues are stored in the rectum until the bee gets rid of them outside the cell from the anus, and from the autopsy results, the forager honeybee workers are yellow. As a result of emptying, its walls are slightly shrunken and have fine lines.

Secondly, the back part, known as the rectum, is enlarged, and elongated, opening into the cavity of the stinging machine, from the results of the anatomical study that was conducted, it was found that the rectum connects from the front to the back of the small intestine (ileum), which is a cylindrical part, and from the backside, it is in the form of a tube that leads to the anus. The rectum is known to contain a large number of waste products before it is discharged into the outside of the cell, this was evident in Figure 4 showing (A) midgut (Mig), (B) ileum (IL), (C) Rectum (Rect) in the control group.

In the second set (the group treated with $\left(\mathrm{LC}_{50}=13.700 \mathrm{mg} / \mathrm{L}\right)$ of tau-fluvalinate) of results of the anatomical study that was conducted, it was found that the midgut after treatment appears to be torn and incoherent, and it appears to be shrinking. At the same time the ileum after treatment with the insecticide became transparent, its walls shrunk, and thin lines appeared. From the results of this anatomical study, it was found that the rectum, after treatment with tau-fluvalinate, had very thin walls that were almost 
lacerated, this was evident in Figure 4 showing (D) midgut (Mig), (E) ileum (IL), (F) Rectum (Rect) in the group treated with tau-fluvalinate.

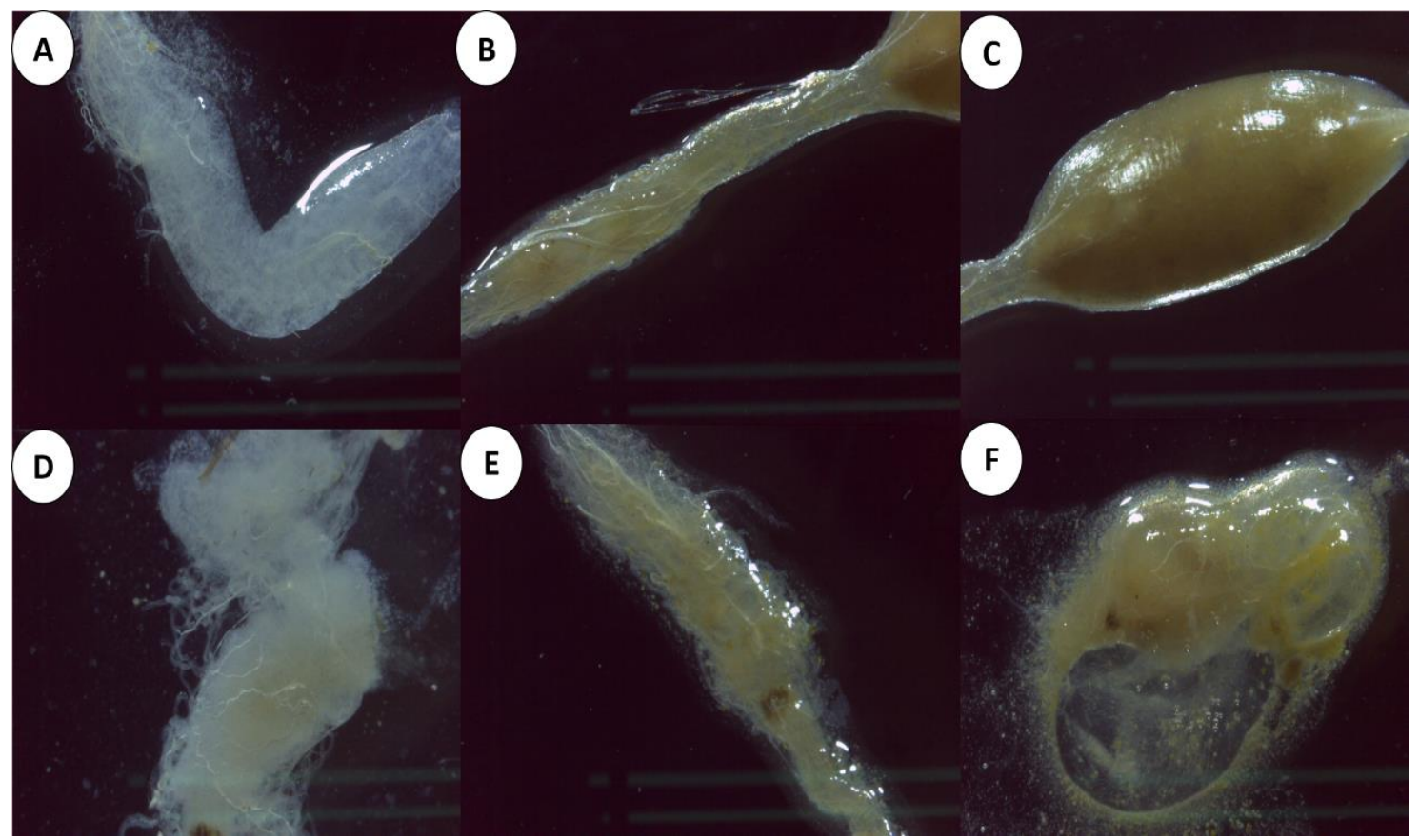

Figure 4. The anatomical structure of the forager honeybee workers, (A) midgut (Mig), (B) ileum (IL), (C) Rectum (Rect) in the Control group. (D) midgut (Mig), (E) ileum (IL), (F)

Rectum (Rect) in the group treated with tau-fluvalinate $(x-40)$

\section{Discussion}

Recently, the widespread distribution of pesticides found in the hive has posed serious concerns regarding pesticide exposure on honeybees (Apis mellifera L.), a honeybee rearing system was adapted to determine the chronic oral toxicity of certain pesticides on honeybees (Apis mellifera L.) (Zhu et al., 2014). Tau-fluvalinate, a popular pyrethroid pesticide, is commonly used as an acaricide in honeybee hives to combat the devastating Varroa mite ( $\mathrm{Wu}$ et al., 2020). And it was discovered to be extremely persistent in the hive, with a half-life of around 5 years in beeswax (Bogdanov, 2006). Fluvalinate's long-term use as an apicultural tool, combined with its absorption by wax in the hive, has resulted in a high level of fluvalinate residue in bee colonies all over the world (Johnson et al., 2010).

Our findings indicate that feeding on common pesticide ingredients, including the miticide fluvalinate, has statistically significant effects on honeybee survival, after $96 \mathrm{~h}$ of feeding, and a significant increase in adult worker mortality was observed after treatment. On the other hand, the laboratory toxicological lines of the tau-fluvalinate and the statistical constants derived from them showed the difference of the lethal concentration values for half of the number of tested adult workers $50 \%, 90 \%$ and also for $99 \%$, which is known as $\mathrm{LC}_{50}, \mathrm{LC}_{90}$, and $\mathrm{LC}_{99}$, and treatment with the taufluvalinate pesticide at $13.700,175.628,1404.975 \mathrm{mg} / \mathrm{L}$ concentrations, respectively. In a study by Ardalani et al. (2021) Bees were split into two classes and fed either a quercetin-sucrose paste or just sucrose for $72 \mathrm{~h}$ to see if dietary quercetin affected the contents of tau-fluvalinate. After that, touch-exposed to $0.9 \mathrm{mg} / \mathrm{bee}$ tau-fluvalinate, no 
significant effect on tau-fluvalinate concentration was observed in bees fed quercetin after $1 \mathrm{~h}$ of oral exposure or $24 \mathrm{~h}$ of contact exposure. In their hives, honeybees are frequently exposed to tau-fluvalinate. Because of its low acute toxicity to honeybees, acute tau-fluvalinate poisoning is uncommon. The toxicity of tau-fluvalinate and tebuconazole to honeybees is low ( $\mathrm{LD}_{50} 1 / 412 \mathrm{mg} / \mathrm{bee}$ and $>200 \mathrm{mg} / \mathrm{bee}$, respectively), but research into the mechanisms that contribute to acaricide and fungicide metabolization is necessary to establish synergistic and antagonistic interactions with natural xenobiotics (European Food Safety Authority, 2010). During an 8-week procedure, up to $10 \%$ of the tau-fluvalinate in a single strip can diffuse from the plastic strip formulation into the hive matrices (Bogdanov et al., 1998).

From our results, we conclude that confidence intervals ranged from the minimum to the upper limit corresponding to these concentrations from $(10.615,19.541 \mathrm{mg} / \mathrm{L})$, $(80.282,856.068 \mathrm{mg} / \mathrm{L})$, and $(380.443,20474.99 \mathrm{mg} / \mathrm{L})$ respectively, at a 95\% confidence level. On the other hand, our results are not consistent with a study by Johnson et al. (2009) who discovered that tau-fluvalinate is safe for bees under normal circumstance since certain subfamilies of honeybees can efficiently metabolize fluvalinate (Mao et al., 2011). There have been several studies that indicate that high oral fluvalinate treatments have the most negative effects on sucrose responsiveness, whereas control dermal treatments have the least negative effect. Oral procedures seemed to decrease responsiveness in general, which may be due to an antifeedant effect that is more pronounced when honeybees ingest compounds directly (Frost et al., 2013). Furthermore, only oral fluvalinate treatments induced distinct probosci extension behaviors, implying that the high fluvalinate dose (a 10-fold improvement over the loworal dose) has distinct behavioral effects (e.g. hyperexcitability of muscles). Physiologically, pharmacological activity can disrupt normal feeding (Frost et al., 2013). Fluvalinate mortality rates have been reported to be variable (LD50 of $0.97 \mu \mathrm{g}$ per honeybee; Santiago, et al., 2000). In general, there have been several studies that indicate fluvalinate mortality rates rise with dosage and that fluvalinate is more lethal when applied orally rather than topically (Frost et al., 2013), this was consistent with our study.

It is evident from the results of the current study that there is a direct relationship between the time of exposure to the pesticide and its effect on the survival of adult workers. The greater the duration of exposure to this pesticide was, the fewer number of the adult workers and the lower their chance of survival was. It is possible that honeybee detoxification processes are not triggered by long-term exposure to low concentrations of active substances, but that honeybee susceptibilities are influenced by higher, more acute concentrations. Also, due to the time required for pesticide bioaccumulation, bee mortality would be latent, which would be preferred by more lipophilic pesticides like fluvalinate as described in the report (Johnson et al., 2013). On the same side, workers who received honey/pollen paste and were exposed to nestmates fared better than all other groups in terms of survival, led by workers who received lactalbumin and were exposed to nestmates, who lived substantially longer than all other groups (Retschnig et al., 2021). When compared to longer-lived workers who ate pollen, negative impact of the antibiotic treatment could be greater in pollen-deprived and therefore short-lived workers (Ricigliano and Simone-Finstrom, 2020). The results by Moro et al. (2021) suggest a shift in host resistance mechanisms within three years. Although the mechanistic explanations of how mites and bees are adapting to each other are currently lacking and call for a holistic view of this particular host-parasite system, 
including investigations of mite and bee traits in the very same populations over time. Such an approach is required to finally enable a more complete mechanistic understanding of the ability of Apis mellifera colonies to survive infestations by Varroa destructor through natural selection. This may also offer an avenue towards more sustainable beekeeping with Apis mellifera globally.

Therefore, adult workers may be exposed to many factors, whether inside or outside the hive. These study findings found the forager honeybee workers when they were exposed to concentration $\left(\mathrm{LC}_{50}\right)$ for four days, the midgut was appearing to be torn and incoherent, and it appears to be shrinking. while the ileum after treatment with the taufluvalinate, became transparent and its walls shrunk, and thin lines appeared. On the other hand, in the rectum, it was found that the rectum, after treatment with taufluvalinate had very thin walls that were almost lacerated. That is consistent with other studies when they found adult honeybee health more affected by pesticides. In a study by $\mathrm{Wu}$ et al. (2020), we found that antibiotic treatment significantly attenuated the expression of certain key detox honeybee cytochrome P450s (P450s) in the midgut, and that co-treatment of antibiotics with thiacloprid and fluvalinate led to reduced survivorship and increased pesticide residues within the honeybee, suggesting that dysbiosis resulting from antibiotic exposure affects honeybee detoxification capability and honeybee health.

As well, in the anatomical study that was shown the ileum which gets rid of body remnants and wastes and absorbs water, food residues are stored in the rectum until the bee gets rid of them outside the cell from the anus, and the autopsy results showed that the forager honeybee workers are yellow. As a result of emptying, its walls are slightly shrunken and have fine lines. That is consistent with other studies the Apis mellifera ileum is a relatively small organ between the midgut and the rectum that has deep infoldings that provide surface area for the absorption of nutrients not collected in the midgut (Mutinelli, 2021).

The study by van Engelsdorp (2009) forward methods using dissections with dissecting microscopes to find pathologies and describe these pathologies both for adult bees of different ages in healthy colonies and also for adult bees from collapsing colonies and bees in apiaries with CCD. Colonies near collapsing colonies are at a high risk of dying, according to previous studies. Many references and manuals have been written about how to diagnose diseases and pests that might be present in the colony. Thymol powder has the highest efficacy against Varroa mites, with $73.72 \%$ mite mortality, followed by formic acid with $72.23 \%$, and fluvalinate strips with $69.21 \%$ mite mortality (Ahmad, et al., 2013). Besides, a study by Shoukry et al. (2013) discovered formic acid $60 \%$ had a lower effect on honeybee drone mating potential than oxalic acid, fluvalinate, thymol, and amitraz. Most of the research focused on the comparison of essential oils and chemical materials.

\section{Conclusion}

Laboratory monitoring of acute effects on the honeybee, Apis mellifera, is usually the first step in assessing chemical hazards for bees. The ability to extrapolate acute effects observed in one of the most important agricultural pollinators the honeybee, and longer exposure times, are critical for a thorough risk assessment. Furthermore, the findings of our research have revealed some adverse effects of tau-fluvalinate on forager honeybees Apis mellifera jemenatica, at least in preliminary testing and under laboratory 
conditions. Further research into the effects of sub-lethal doses of tau-fluvalinate on honeybees is urgently needed, particularly because honeybees are frequently exposed to sub-lethal doses of it.

Conflict of interests. The author declares no conflict of interests.

\section{REFERENCES}

[1] Abbott, W. S. (1925): A method of computing the effectiveness of an insecticide. Journal of Economic Entomology 18: 265-267. DOI: https://doi.org/10.1093/jee/18.2.265a.

[2] Abd El-Wahab, T. E., Shalaby, S. E. M., Al-Kahtani, S. N., et al. (2021): Mode of application of acaricides against the ectoparasitic mite (Varroa destructor) infesting honeybee colonies, determines their efficiencies and residues in honey and beeswax. Journal of King Saud University - Science 33: 101236. DOI: 10.1016/j.jksus.2020.101236.

[3] Ahmad, K. J., Razzaq, A., Abbasi, K. H., Shafiq, M., Saleem, M. Arshadullah, M. (2013): Thymol as control agent of mites (Varroa destructor) on honeybees (Apis mellifera). Pakistan J Agri Res 26: 316-320.

[4] Aljedani, D. M. (2017): Detection of toxicity and effects of some insecticides to local honey bee race (Apis mellifera jemenatica). - Journal of American Science 13: 19-31. DOI: $10.7537 /$ marsjas130317.04.

[5] Allam, S. F. M., Hassan, M. F., Hassan, A. S., Abada, M. K. A. (2021): Simple approaches for environmental and mechanical management of the Varroa mite, Varroa destructor Anderson and Trueman (Parasitiformes: Varroidae), on the honey bee, Apis mellifera L. (Hymenoptera: Apidae) in Egypt. - Egyptian Journal of Biological Pest Control 31. DOI: 10.1186/s41938-021-00368-8.

[6] Ardalani, H., Vidkjær, N. H., Laursen, B. B., et al. (2021): Dietary quercetin impacts the concentration of pesticides in honey bees. - Chemosphere 262: 127848. DOI: 10.1016/j.chemosphere.2020.127848.

[7] Baker, N. T., Richards, A. G., Cook, E. F. (1982): Reexamination of the exoskeletal and muscular anatomy of the honey bee, Apis mellifera, L and a polarized light microscopy technique for morphological studies. - Annals of the Entomological Society of America 75: 494-497. DOI: 10.1093/aesa/75.5.494.

[8] Bogdanov, S., Kilchenmann, V., Imdorf, A. (1998): Acaricide residues in some bee products. - Journal of Apicultural Research 37: 57-67. DOI: 10.1080/00218839.1998.11100956.

[9] Bogdanov, S. B. (2006): Contaminants of bee products. - Apidologie 37: 1-18.

[10] Brancato, A., Brocca, D., Carrasco Cabrera, L., et al. (2018): Review of the existing maximum residue levels for tau-fluvalinate according to Article 12 of Regulation (EC) No 396/2005. - EFSA Journal 16. DOI: 10.2903/j.efsa.2018.5475.

[11] Carreck, N. L., Andree, M., Brent, C. S., et al. (2013): Standard methods for Apis mellifera anatomy and dissection. - Journal of Apicultural Research 52. DOI: 10.3896/IBRA.1.52.4.03.

[12] Davidson, G. (2021): Honey Bee Pharmacology. - In: Kane, T. R., Faux, C. M. (eds.) Honey Bee Medicine for the Veterinary Practitioner. Wiley \& Sons, Inc., Hoboken, NJ, pp 135-148.

[13] Davies, T. G. E., Field, L. M., Usherwood, P. N. R., Williamson, M. S. (2007): DDT, pyrethrins, pyrethroids and insect sodium channels. - IUBMB Life 59: 151-162. DOI: $10.1080 / 15216540701352042$. 
[14] European Food Safety Authority (2010): Conclusion on the peer review of the pesticide risk assessment of the active substance bromadiolone. - EFSA Journal 8: 1-102. DOI: 10.2903/j.efsa.2010.1783.

[15] Frost, E. H., Shutler, D., Hillier, N. K. (2013): Effects of fluvalinate on honey bee learning, memory, responsiveness to sucrose, and survival. - Journal of Experimental Biology 216: 2931-2938. DOI: 10.1242/jeb.086538.

[16] Gisder, S., Genersch, E. (2020): Direct evidence for infection of Varroa destructor mites with the bee-pathogenic deformed wing virus variant $B$, but not variant $A$, via fluorescence in situ hybridization analysis. - Journal of Virology 95: 1-15. DOI: 10.1128/jvi.01786-20.

[17] Johnson, R. M., Wen, Z., Schuler, M. A., Berenbaum, M. R. (2009): Mediation of pyrethroid insecticide toxicity to honey bees (Hymenoptera: Apidae) by cytochrome P450 monooxygenases. - Journal of Economic Entomology 99: 1046-1050. DOI: 10.1603/0022-0493-99.4.1046.

[18] Johnson, R. M., Ellis, M. D., Mullin, C. A., Frazier, M. (2010): Pesticides and honey bee toxicity - USA. - Apidologie 41: 312-331. DOI: 10.1051/apido/2010018.

[19] Johnson, R. M., Dahlgren, L., Siegfried, B. D., Ellis, M. D. (2013): Acaricide, fungicide and drug interactions in honey bees (Apis mellifera). - PLoS ONE 8. DOI: 10.1371/journal.pone.0054092.

[20] Kakamand, F., Mahmoud, T., Amin, A. (2008): The role of three insecticides in disturbance the midgut tissue in honey bee Apis mellifera L. workers. - Journal of Dohuk University, Iraq 11: 144-151.

[21] Mao, W., Schuler, M. A., Berenbaum, M. R. (2011): CYP9Q-mediated detoxification of acaricides in the honey bee (Apis mellifera). - Proceedings of the National Academy of Sciences of the United States of America 108: 12657-12662. DOI: 10.1073/pnas.1109535108.

[22] Moro, A., Blacquière, T., Panziera, D., et al. (2021): Host-parasite co-evolution in realtime: changes in honey bee resistance mechanisms and mite reproductive strategies. Insects 12: 1-13. DOI: 10.3390/insects12020120.

[23] Mutinelli, F. (2021): Euthanasia and welfare of managed honey bee colonies. - Journal of Apicultural Research 0: 1-9. DOI: 10.1080/00218839.2021.1895569.

[24] OECD (2017): OECD GD 245: Honeybees (Apis mellifera, L.), chronic oral toxicity test (10-day feeding). - OECD Guidelines for the Testing of Chemicals 1-7.

[25] Potts, S. G., Roberts, S. P. M., Dean, R., et al. (2010): Declines of managed honey bees and beekeepers in Europe. - Journal of Apicultural Research 49: 15-22. DOI: 10.3896/IBRA.1.49.1.02.

[26] Qi, S., Niu, X., Wang, D. H., et al. (2020): Flumethrin at sublethal concentrations induces stresses in adult honey bees (Apis mellifera L.). - Science of the Total Environment 700: 134500. DOI: 10.1016/j.scitotenv.2019.134500.

[27] Rangel, J. R., Tarpy, D. (2016): In-hive miticides and their effect on queen supersedure and colony growth in the honey bee (Apis mellifera). - Journal of Environmental \& Analytical Toxicology 06: DOI: 10.4172/2161-0525.1000377.

[28] Retschnig, G., Rich, J., Crailsheim, K., et al. (2021): You are what you eat: relative importance of diet, gut microbiota and nestmates for honey bee, Apis mellifera, worker health. - Apidologie. DOI: 10.1007/s13592-021-00851-z.

[29] Ricigliano, V. A., Simone-Finstrom, M. (2020): Nutritional and prebiotic efficacy of the microalga Arthrospira platensis (spirulina) in honey bees. - Apidologie 51: 898-910. DOI: 10.1007/s13592-020-00770-5.

[30] Santiago, G. P., Otero-Colina, G., Sánchez, D. M., Guzmán, M. E. R., Vandame, R. (2000): Comparing effects of three acaricides on Varroa jacobsoni (Acari: Varroidae) and Apis mellifera (Hymenoptera: Apidae) using two application techniques. - Fla Entomol 83: 468-476. DOI: doi.org/10.2307/3496722. 
[31] Sara, C., Mar, Ó., Calatayud, F., et al. (2021): Large-scale monitoring of resistance to coumaphos, amitraz, and pyrethroids in Varroa destructor. - Insects 12: 27. DOI: https://doi.org/10.3390/insects12010027.

[32] Semkiw, P., Skubida, P., Pohorecka, K. (2013): Skuteczność zwalczania roztoczy Varroa Destructor paskami z amitrazem po wieloletnim stosowaniu tej substancji w pasiekach. Journal of Apicultural Science 57: 107-121. DOI: 10.2478/jas-2013-0012.

[33] Shoukry, R. S., Khattaby, A. M., El-Sheakh, A. A., et al. (2013): Effect of some materials for controlling varroa mite on the honeybee drones (Apis mellifera L.). - Egyptian Journal of Agricultural Research 91: 825-834.

[34] VanEngelsdorp, D., Evans, J. D., Saegerman, C., et al. (2009): Colony collapse disorder: a descriptive study. - PLoS ONE 4. DOI: 10.1371/journal.pone.0006481.

[35] VanEngelsdorp, D., Traynor, K. S., Andree, M., et al. (2017): Colony Collapse Disorder (CCD) and bee age impact honey bee pathophysiology. - PLoS ONE 12: 1-23. DOI: 10.1371/journal.pone.0179535.

[36] Vojvodic, S., Rehan, S. M., Anderson, K. E. (2013): Microbial gut diversity of Africanized and European honey bee larval instars. - PLoS ONE 8. DOI: 10.1371/journal.pone.0072106.

[37] Wu, Y., Zheng, Y., Chen, Y., et al. (2020): Honey bee (Apis mellifera) gut microbiota promotes host endogenous detoxification capability via regulation of P450 gene expression in the digestive tract. - Microbial Biotechnology 13: 1201-1212. DOI: 10.1111/1751-7915.13579.

[38] Zhu, W., Schmehl, D. R., Mullin, C. A., Frazier, J. L. (2014): Four common pesticides, their mixtures and a formulation solvent in the hive environment have high oral toxicity to honey bee larvae. - PLoS ONE 9. DOI: 10.1371/journal.pone.0077547. 